\title{
Mange Caused by Sarcoptes scabiei (Acari: Sarcoptidae) in Wild Raccoon Dogs, Nyctereutes procyonoides, in Kanagawa Prefecture, Japan
}

\author{
Mamoru TAKAHASHI ${ }^{1)}$, Sadao NOGAMI ${ }^{2) *}$, Hitoko MISUMI ${ }^{1)}$, Soichi MARUYAMA ${ }^{2)}$, Takashi SHIIBASHI ${ }^{2}$, \\ Yoshiro YAMAMOTO ${ }^{3)}$ and Takeo $\mathrm{SAKAI}^{2)}$ \\ ${ }^{1)}$ Department of Medical Zoology, Saitama Medical School, Moroyama-machi, Saitama 350-0451, ${ }^{2)}$ Department of Veterinary Medicine, \\ College of Bioresource Sciences, Nihon University, Kameino, Fujisawa, Kanagawa 252-8510 and ${ }^{3)}$ Kanazawa Zoological Gardens of \\ Yokohama City, Kanazawa, Yokohama, Kanagawa 236-0042, Japan
}

(Received 11 September 2000/Accepted 25 December 2000)

ABSTRACT. Parasitological and histopathological examinations were performed in 25 raccoon dogs (Nyctereutes procyonoides) obtained in Kanagawa Prefecture, Japan, all of which were found to be heavily infected with Sarcoptes scabiei. The mites detected on these raccoon dogs were morphologically indistinguishable from the human species, and no Demodex mites were detected. Histopathological examinations showed prominent hyperkeratosis and acanthosis with eczema, and numerous burrows containing mites were observed in the epidermis. The enzootic dermatitis of wild raccoon dogs in recent years was clearly demonstrated to be caused by $S$. scabiei in the present study.

KEY WORDS: Nyctereutes procyonoides, raccoon dog, Sarcoptes scabiei.

J. Vet. Med. Sci. 63(4): 457-460, 2001

Over the past several years, mammalogists, taxidermists and hunters informed us that they collected partially hairless raccoon dogs, Nyctereutes procyonoides (Gray, 1834), in Kanagawa and Saitama prefectures, Japan (personal communications). This information suggested that those raccoon dogs might be infected with sarcoptic mites. Sarcoptic mange is a skin disease caused by Sarcoptes scabiei and has been described mainly in wild canid populations such as coyotes, foxes and wolves in North America and Europe [13-15, 22]. The importance of human sarcoptic mange has recently been emphasized and yet, human infestations with non-human strains of $S$. scabiei have been reported, most frequently transmitted by way of dogs, camels, horses, pigs, goats, sheeps, ferrets or other domesticated mammals [2, 3, $6-8,10,16-18,20,21]$. Mange of wild raccoon dogs in Japan was first reported by Suzuki et al. [19], who described four cases, however, few cases have been reported in recent years. In the present study, the mange of raccoon dogs was studied in more detail, with the morphology of the mites and the resultant dermal pathology in a relatively large number of affected animals.

Many wild raccoon dogs, diseased or injured in traffic accidents or others around Yokohama City in Kanagawa Prefecture, Japan, were brought to the Kanazawa Zoological Gardens of Yokohama City for care and medical treatment. Twenty-five raccoon dogs that died in the facility despite treatment were examined in the present study. After confirming sarcoptic mange by macroscopic examination of the animals, we took hairless or hyperkeratotic skin lesions from each animal by punch biopsy. The skin samples were soaked in $10 \% \mathrm{KOH}$ solution for 6-12 hr, and then mounted

\footnotetext{
* Correspondence to: Nogami, S., Department of Veterinary Medicine, Nihon University, 1866 Kameino, Fujisawa, Kanagawa 252-8510, Japan.
}

on a slide for microscopic examination. Five $8.04 \mathrm{~mm}^{2}$ microscopic fields were selected at random, and all sarcoptic mites of different developmental stages (egg, larva, nymph, female and male adult) in the fields were counted to determine prevalence of the mites. For histopathological examination, skin samples were removed from each animal with obvious clinical signs of sarcoptic mange, fixed in $10 \%$ buffered formalin and embedded in paraffin. One hundred or more serial sections, $7-\mu \mathrm{m}$ thick, were prepared from each specimen and stained with hematoxylin and eosin.

All the 25 raccoon dogs with advanced active mange were infected with S. scabiei, and more than one-half of their body surface was affected. The skin was seriously affected and the hair was lost at varying degrees. The affected skin was thickened, wrinkled, slate-gray in color and partially covered with numerous suppurative scabs (Fig. $1)$.

Microscopic observation of keratinized epidermal specimens treated with $\mathrm{KOH}$ revealed the presence of different stages of sarcoptic mites (Fig. 2). The mites were morphologically identified as S. scabiei (Fig. 3). Demodex species were not observed. The largest number of S. scabiei observed was 32.8 in raccoon dog No. 17, and the lowest was 5.6 in No. 3 (Table 1). All the developmental stages of mite were observed in all the animals except No. 3 .

In the histological sections of skin lesions, hyperkeratosis, parakeratosis and acanthosis were observed in the epidermis and papillomatosis was in the dermis. The upper part of the epidermis appeared to be hollowed by numerous burrows, some of which included mites. The junction between the stratum lucidum and stratum granulosum was unclear and was irregularly depressed by burrowing mites, and an altered cellular arrangement was seen. The stratum granulosum was destroyed for some distance by the burrowing mites (Fig. 4). 


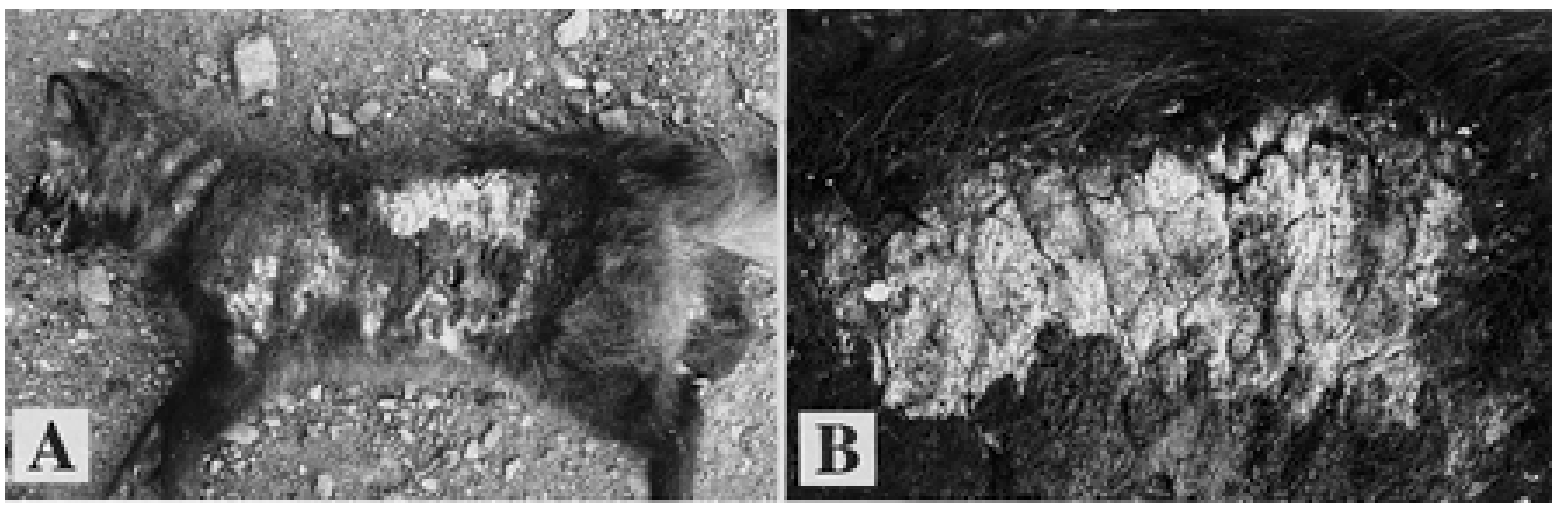

Fig. 1. Advanced case of active sarcoptic mange in a raccoon dog. A, partial to almost total alopecia, with thickened or wrinkled skin, distributing over the body surface; B, magnification of Fig. 1A showing slate-gray thickened, hairless skin with complete alopecia.

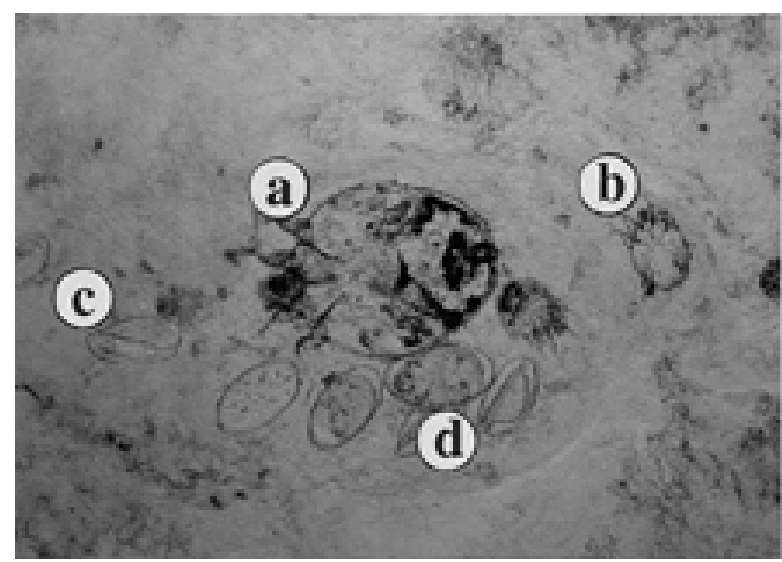

Fig. 2. Microscopy of a fragment of hairless skin from a raccoon dog, showing the different stages of Sarcoptes scabiei, a female (a), larvae (b), egg shells (c) and embryonated eggs (d).

Sarcoptes scabiei mites are ectoparasitic in humans and other mammals but have host preference, although no notable morphological differences are present among the mites from different hosts. Fain [5] studied the morphology of a large number of S. scabiei mites from 80 host mammals including humans and, domestic and wild animals, and concluded that $S$. scabiei should be recognized as a single, highly variable species. Zahler et al. [23] reported that the genus Sarcoptes consists of a single, heterogenous species genotypically. Sarcoptes scabiei from wild raccoon dogs in the present study was compared with $S$. scabiei var. hominis in the number and characterization of setae on the dorsal and ventral shields of adult males and females. However, these two forms of mites were morphologically indistinguishable from each other, as Mellanby [12], Fain [5] and Kano [9] reported.

The enzootic infection of 4 hairless raccoon dogs with sarcoptic mange mites, S. scabiei, was first reported in Gifu Prefecture, Japan, by Suzuki et al. in 1981 [19]. These raccoon dogs were infected with about 10 mites per $25 \mathrm{~cm}^{2}$ of the skin. This average number of mites was lower than that by us (Table 1), although some inconsistencies seemed to exist in collection data such as sampled sites and age of the infected host.

Sarcoptes mites will be transmitted among the members of families, which may account in part for the increase of prevalence in the whole population of raccoon dogs. Although the effects of sarcoptic mange on raccoon dog populations have not been determined in Japan, Pence and Windberg [13] examined the effects of epizootic sarcoptic mange on coyote populations in Texas and reported that reduced ovulation and pregnancy rates occurred in adult females with a serious mange. Analysis of the long-term population dynamics is necessary to clarify the effects of sarcoptic mange on wild raccoon dog populations in Japan.

It was shown experimentally that generally, Sarcoptes mites of an animal origin infected temporarily and do not lay eggs in humans [1]. Nevertheless, attention should be paid to animals infected with $S$. scabiei since Sarcoptes mites infesting cats or monkeys have been reported to be transferred onto humans and to cause scabies similar to that of Norwegian type $[4,7,11]$. Field mammalogists, environmental researchers, hunters and other persons who come in close contact with wild mammals should also take care of the infestations with the mites from wild animals.

\section{REFERENCES}

1. Alexander, J. O. D. 1984. Arthropods and Human Skin. Springer-Verlag.

2. Buxton, P. A. 1921. Parasitology 13: 114-145.

3. Camerom, A. E. 1924. Parasitology 16: 255-265.

4. Estes, S. A., Kummel, B. and Arlian, L. G. 1983. J. Am. Acad. Dermatol. 9: 397-401.

5. Fain, A. 1968. Acta Zool. Pathol. Antverpiensia 47: 1-196.

6. Fain, A. 1978. Int. J. Dermatol. 17: 20-30.

7. Goldman, L. and Feldman, M. D. 1949. Arch. Dermatol. Syphilol. 59: 175-178.

8. Imai, S., Ike, K., Togo, M., Kinoshita, M., Tashiro, H., Ishii, T and Shimada, K. 1983. J. Jpn. Vet. Med. Assoc. 36: 469-472.

9. Kano, R. 1999. Arthropods and Dermatology., Tokai Univer- 

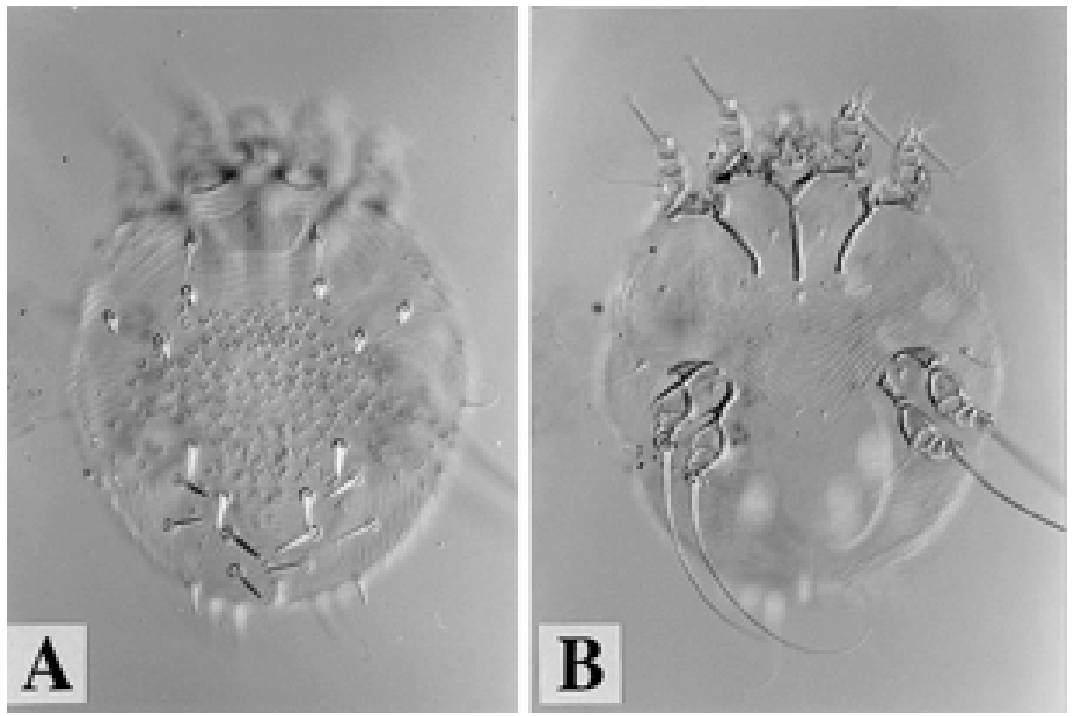

Fig. 3. Female Sarcoptes scabiei found on a raccoon dog. A, dorsal view; B, ventral view.

Table 1. Mean number of Sarcoptes scabiei mites per $8.04 \mathrm{~mm}^{2}$ of skin in raccoon dogs $(n=5)$

\begin{tabular}{lccccrr}
\hline \multirow{2}{*}{$\begin{array}{l}\text { Sample } \\
\text { no. }\end{array}$} & \multicolumn{2}{c}{ Adult } & Nymph & Larva & Egg & Total \\
\cline { 2 - 3 } 1 & Male & Female & & & & \\
2 & 1.2 & 1.6 & 5.6 & 2.2 & 7.4 & 18.0 \\
3 & 2.8 & 3.6 & 4.0 & 1.4 & 15.0 & 26.8 \\
4 & 0.4 & 0.6 & 3.4 & 1.2 & 0 & 5.6 \\
5 & 1.2 & 1.8 & 6.2 & 1.0 & 4.8 & 15.0 \\
6 & 1.8 & 2.6 & 7.6 & 1.6 & 9.8 & 23.4 \\
7 & 1.0 & 0.6 & 1.8 & 2.0 & 15.8 & 20.6 \\
8 & 0.4 & 1.8 & 3.8 & 1.4 & 11.4 & 19.4 \\
9 & 1.8 & 1.8 & 3.2 & 1.6 & 10.8 & 17.2 \\
10 & 0.8 & 2.4 & 5.2 & 1.0 & 3.2 & 10.8 \\
11 & 1.4 & 2.4 & 7.8 & 1.8 & 8.4 & 18.2 \\
12 & 0.4 & 0.8 & 2.4 & 0.6 & 4.4 & 17.8 \\
13 & 1.6 & 2.4 & 5.4 & 2.4 & 12.4 & 8.4 \\
14 & 1.2 & 0.6 & 4.6 & 0.6 & 2.6 & 9.6 \\
15 & 2.0 & 1.2 & 3.4 & 0.2 & 2.6 & 9.4 \\
16 & 3.0 & 1.8 & 5.4 & 1.8 & 17.4 & 29.4 \\
17 & 0.4 & 2.0 & 3.4 & 0.8 & 26.2 & 32.8 \\
18 & 3.6 & 3.0 & 14.0 & 2.8 & 6.8 & 30.2 \\
19 & 0.4 & 1.2 & 4.0 & 1.0 & 7.2 & 13.8 \\
20 & 0.4 & 0.8 & 2.4 & 0.8 & 3.6 & 8.0 \\
21 & 0.8 & 1.8 & 4.6 & 0.6 & 1.0 & 8.8 \\
22 & 0.6 & 1.6 & 4.4 & 2.0 & 11.4 & 20.0 \\
23 & 0.4 & 0.8 & 2.4 & 3.8 & 14.8 & 22.2 \\
24 & 0.2 & 1.0 & 4.8 & 2.2 & 9.8 & 18.0 \\
25 & 1.6 & 2.6 & 7.8 & 1.8 & 10.2 & 24.0 \\
\hline & & & & & &
\end{tabular}

sity Press, Tokyo.

10. Kutzer, E. and Grunberg, W. 1967. Z. Parasitenkd 29: 46-60.

11. Maldonado, R. R., Tamayo, L., Dominguez, J. and Mexico, I. 1977. Arch. Dermatol. 113: 1733.

12. Mellanby, K. 1972. Scabies, E. W. Classey, Hampton.

13. Pence, D. B. and Windberg, L. A. 1994. J. Wildl. Manage. 58:
624-633.

14. Pence, D. B., Windberg, L. A., Pence, B. C. and Sprowls, R. 1983. J. Parasitol. 69: 1100-1115.

15. Pence, D. B., Casto, S. D. and Samuel, W. M. 1975. Acarologia 17: 160-165.

16. Rook, A. 1977. Recent Adv. Dermatol. 4: 73-88. 

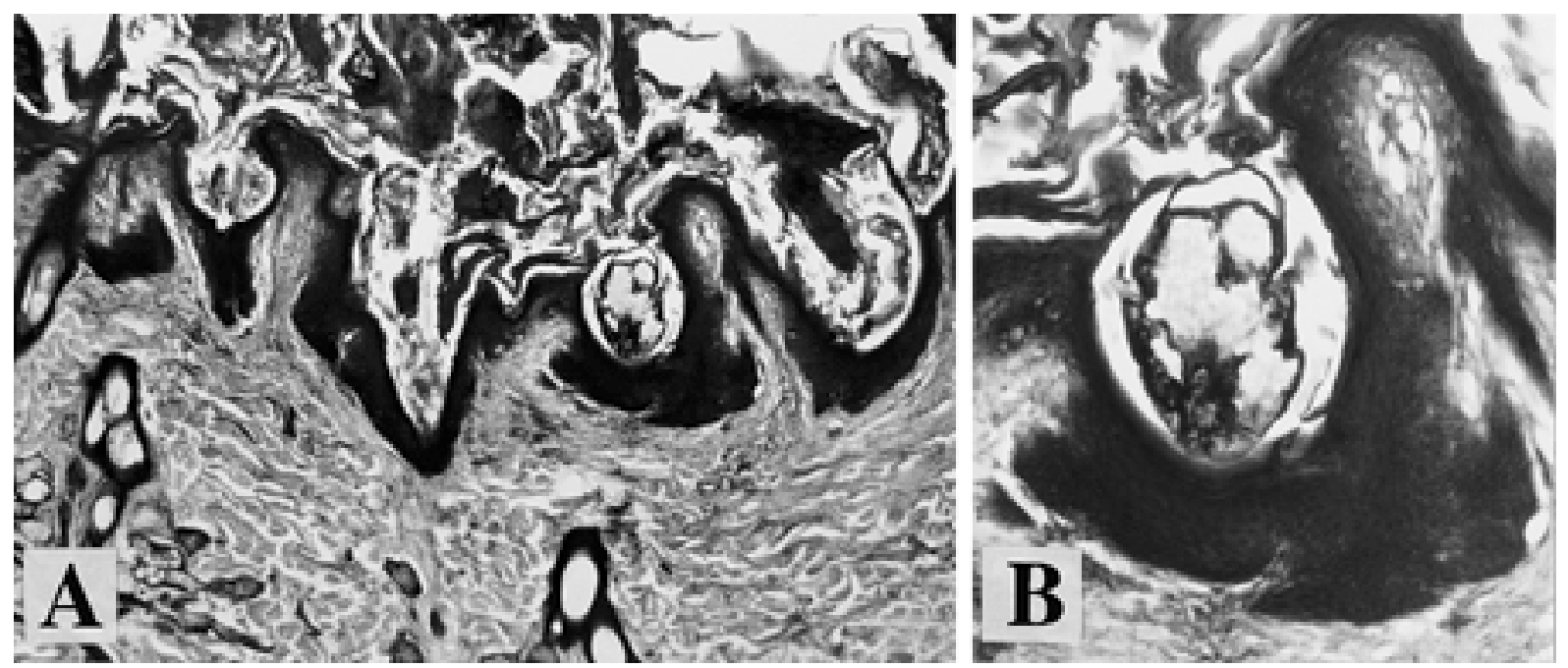

Fig. 4. Histopathological findings of skin lesions from a raccoon dog with hyperkeratotic scabies. A, many Sarcoptes scabiei mites can be seen in the burrows in the stratum corneum. The stratum papillare in the dermis was also infiltrated with lymphocytes and eosinophils; B, magnification of Fig. 4A. An adult female $S$. scabiei can be seen in a burrow. The mouthparts found at the lower part of body reached the stratum granulosum of the epidermis.

17. Sequeira, J. H. 1925. Proc. R. Soc. Med. 18: 45-56.

18. Smith, E. B. and Claypoole, T. F. 1967. J. Am. Med. Assoc. 199: $95-100$

19. Suzuki, Y., Sugimura, M. and Kaneko, K. 1981. Res. Bull. Fac. Agric. Gifu Univ. 45: 151-156.

20. Thomsett, L. R. 1968. Br. Med. J. 3: 93-95.
21. Toomey, N. 1922. Urol. Cutaneous Rev. 26: 473-489.

22. Trainer, D. O. and Hale, J. B. 1969. Bull. Wildl. Dis. Assoc. 5: 387-391.

23. Zahler, M., Essig, A., Gothe, R. and Rinder, H. 1999. Int. J. Parasitol. 29: 759-766. 